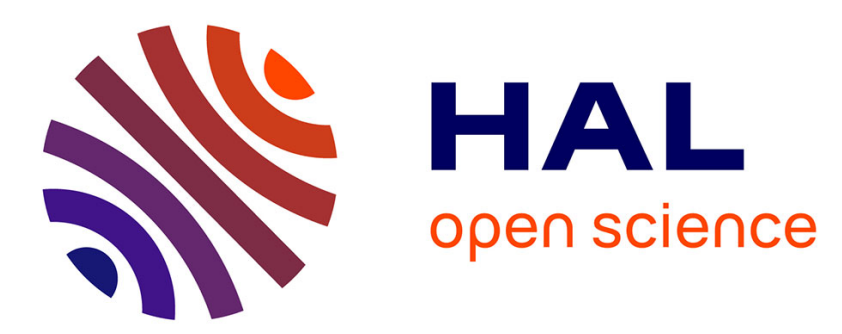

\title{
The Distribution of Boron within the Microstructure of a Ferritic Steel determined using Secondary Ion Mass Spectroscopy
}

\author{
Robert Keith Wild, Peter Heard, Peter Ej Flewitt
}

\section{- To cite this version:}

Robert Keith Wild, Peter Heard, Peter Ej Flewitt. The Distribution of Boron within the Microstructure of a Ferritic Steel determined using Secondary Ion Mass Spectroscopy. Philosophical Magazine, 2006, 86 (09), pp.1277-1286. 10.1080/14786430500325121 . hal-00513615

\section{HAL Id: hal-00513615 \\ https://hal.science/hal-00513615}

Submitted on 1 Sep 2010

HAL is a multi-disciplinary open access archive for the deposit and dissemination of scientific research documents, whether they are published or not. The documents may come from teaching and research institutions in France or abroad, or from public or private research centers.
L'archive ouverte pluridisciplinaire HAL, est destinée au dépôt et à la diffusion de documents scientifiques de niveau recherche, publiés ou non, émanant des établissements d'enseignement et de recherche français ou étrangers, des laboratoires publics ou privés. 


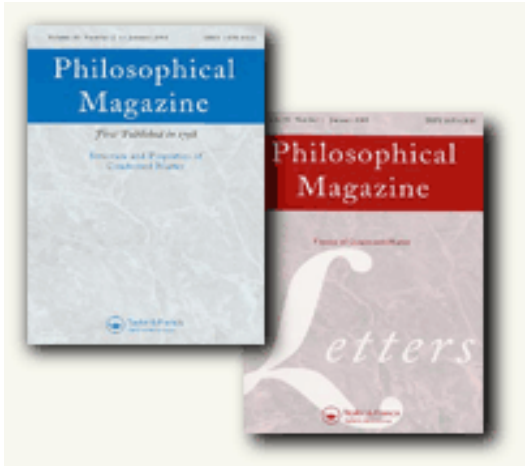

\section{The Distribution of Boron within the Microstructure of a Ferritic Steel determined using Secondary Ion Mass Spectroscopy}

\begin{tabular}{|c|c|}
\hline Journal: & Philosophical Magazine \& Philosophical Magazine Letters \\
\hline Manuscript ID: & TPHM-05-Aug-0370 \\
\hline Journal Selection: & Philosophical Magazine \\
\hline $\begin{array}{r}\text { Date Submitted by the } \\
\text { Author: }\end{array}$ & 19-Aug-2005 \\
\hline Complete List of Authors: & $\begin{array}{l}\text { Wild, Robert; Retired-Bristol University, Interface Analysis Ctr } \\
\text { Heard, Peter; Bristol University, Interface Analysis Centre } \\
\text { Flewitt, Peter; Bristol University, Interface Analysis Centre }\end{array}$ \\
\hline Keywords: & borides, SIMS, microstructure, steel \\
\hline Keywords (user supplied): & \\
\hline
\end{tabular}

\section{(s) ScholaroNE" \\ Manuscript Central}




\title{
The Distribution of Boron within the Microstructure of a Ferritic Steel determined using Secondary Ion Mass Spectroscopy
}

\section{R K Wild ${ }^{1}$, P J Heard ${ }^{1}$ and P E J Flewitt ${ }^{2}$}

${ }^{1,2}$ Interface Analysis Centre and ${ }^{2}$ Department of Physics

University of Bristol H H Wills Laboratory

Oldbury House University of Bristol

Bristol

Bristol

BS2 8BS BS2 8BS

\begin{abstract}
$\underline{\text { Abstract }}$
Boron in ferritic steels at low concentrations can potentially have a significant effect on the mechanical properties. High spatial resolution microanalyses have been undertaken on a normalised C-Mn ferritic steel containing less than $1 \mathrm{wt}$. ppm boron. Secondary ion mass spectroscopy on bulk samples has been used to map the distribution of boron with the overall microstructure. Image analysis has been used to determine the location and concentration of boron within the overall microstructure of the steel. The results are discussed in terms of the microstructure, distribution, detection capability and overall audit of boron.
\end{abstract}

\section{$1 \quad$ Introduction}

Carbon-manganese steels and weld metals are used in the construction of engineering structures because they have a good combination of strength, fracture toughness, workability and weldability (1). Unfortunately together with the major and minor alloying elements they can contain a range of impurity elements (2). Certainly when these steels are subject to equilibrium and non-equilibrium heat treatment cycles or neutron irradiation these elements can redistribute within the overall microstructure $(3,4,5)$. This can result, in particular, in the well established equilibrium and non-equilibrium segregation of certain elements to grain and interphase boundaries. In $\alpha$-iron in contrast to the non-hybridised interaction between $\alpha$-iron and impurity phosphorus, which results in a reduction in grain boundary cohesion, the iron boron hybridisation allows covalent bonding normal to the boundary and this enhances the grain 
boundary cohesion (6). Moreover it has been shown that within C-Mn steels boron can distribute to the various second phase inclusions and carbide and nitride precipitates. Depending upon the particular prior thermo-mechanical history boron was established to be associated with silicate-phase inclusions, $\mathrm{BN}(50$ at $\% \mathrm{~B}), \mathrm{M}_{3}(\mathrm{C}, \mathrm{N})$ type carbide precipitates and oxides $(1,4$,$) .$ Certainly the distribution of the boron within the overall microstructure can have a major influence on the mechanical properties of the steels (7). This can become even more significant if the material is subsequently subject to neutron irradiation (8). As a consequence it is important to be able to measure the distribution of boron present in low $(\leq 5 \mathrm{ppm})$ concentrations within the overall microstructure of such steels to a high spacial resolution. In addition to the distribution and concentration it is also important to be able to establish the chemical state of the boron in order to understand if the element is fixed within the microstructure or if it is free to be further redistributed if subject to subsequent defined thermal or irradiation treatments.

In their previous paper Jones et al (4) considered a range of steels with boron content extending from less than $1 \mathrm{ppm}$ to greater than $40 \mathrm{ppm}$ to contrast the behaviour between low and high boron content ferritic steels. It is the purpose of this paper to consider the potential for very low boron levels in steel to be deleterious, under conditions of neutron irradiation, to the mechanical properties and to understand how the boron is distributed within the steel. In sections 2 and 3 we describe the application of secondary ion mass spectroscopy to establish the distribution and chemical state of boron within the overall microstructure of a low boron containing $(<1 \mathrm{ppm}) \mathrm{C}$ Mn steel plate. This high resolution technique provides elemental distribution maps that enable the quantification of boron containing precipitates. The results are discussed in section 4 with respect to the microstructure, distribution, detection capability and overall audit of boron.

\section{EXPERIMENTAL PROCEDURE}

\subsection{Materials:}

One ferritic steel containing $<1$ wt. ppm boron has been considered, the VSA steel from the Jones et al 2002 study (4). The VSA plate steel is a Si-killed steel produced from a special melt prepared to the BW78 specification. The VSA steel was hot rolled, normalised at a temperature of $1313 \mathrm{~K}$ and then air cooled; no further heat treatment was given after normalisation. The composition of this steel in wt \% is given in Table 1 . It has low concentrations of the elements, $\mathrm{S}, \mathrm{P}, \mathrm{Cu}, \mathrm{Ni}, \mathrm{Mo}$ and $\mathrm{B}$. 


\subsection{Chemical microanalysis:}

Microanalyses were undertaken with secondary ion mass spectroscopy (SIMS) using specimens that were metallographically polished. These specimens were ion-cleaned specimens prior to analysis in a Vacuum Generators 7035 mass spectrometer (VG7035MS) system, fitted with an FEI field emission liquid $\mathrm{Ga}$ ion gun to produce a nominal $20 \mathrm{~nm}$ ultimate beam size. The ion gun was operated at beam currents from 0.1 to $0.2 \mathrm{nA}$ at a beam energy of $25 \mathrm{keV}$. Secondary ions were detected and mass analysed primarily to obtain chemical images of the oxide inclusions and precipitates. To ensure that the distribution of boron was accurately carried out and not confused by other hydro-carbon species, maps were recorded from the two isotopes of boron, ${ }^{10} \mathrm{~B}$ and ${ }^{11} \mathrm{~B}$. An image-processing package (UTHSCSA ImageTool) was then used to determine, from the SIMS elemental maps, the mean size and spacing of the inclusions and precipitates: approximately 100 such features were measured in a field of about $200 \mu \mathrm{m} \mathrm{x}$ $150 \mu \mathrm{m}$.

\section{RESULTS}

The microstructure of the Si-killed plate steel VSA consists of $\sim 10 \%$ pearlite in a matrix of ferrite. The average ferrite grain size is $30 \mu \mathrm{m}$ (mean linear intercept) and in some of the areas the pearlite lamellae have become spheroidised due to the normalising heat treatment. This leads to the formation of small carbide precipitates in the grains as well as at the grain boundaries. In addition Jones et al (2002) have shown that there is a small volume fraction of randomly dispersed $\mathrm{MnS}$ inclusions together with (Fe,Si) oxide and ( $\mathrm{Al}, \mathrm{Mn}, \mathrm{Mg}$ ) silicate precipitates.

The positive SIMS spectrum from the mass range 9.5 to 11.5 recorded from an area of the steel specimen is shown in Figure 1. The natural isotopic ratio of ${ }^{11} \mathrm{~B}:{ }^{10} \mathrm{~B}$ is $81.3: 18.7$ and the areas under the ${ }^{11} \mathrm{~B}$ and ${ }^{10} \mathrm{~B}$ peaks have the ratio 80.4 : 19.6 confirming that these peaks are both from boron.

An ion induced secondary electron image of the surface, Figure 2(a), shows the ferrite grains together with the pearlite. The boron element maps were recorded by fixing the ion detector on masses 10 and 11 respectively while rastering the incident gallium ion beam, Figures 2(b) and 
2(c). Images were recorded from an area $200 \mu \mathrm{m} \times 150 \mu \mathrm{m}$ with a resolution of 640 by 480 pixels. From the maps showing the distribution of ${ }^{10} \mathrm{~B}$ and ${ }^{11} \mathrm{~B}$, Figure $2(\mathrm{~b})$ and (c), it is clear that boron is present in small particles, $\leq 10 \mu \mathrm{m}$ in diameter, and although the signal to noise ratio is less for the ${ }^{10} \mathrm{~B}$ map the two boron images are essentially identical. Figure 3 shows four maps, one is a map for the ion ${ }^{11} \mathrm{~B}$ obtained using an oxygen bleed, figure 3(a), while maps (b), (c) and (d) are for $\mathrm{Al}$ (mass 27), Si (mass 28) and Mn (mass 55). The boron maps show limited correlation with any of the Al, Si and Mn maps. Hence the boron is not present in all particles but is associated with some other element. In addition the Al, Si and $\mathrm{Mn}$ maps also fail to correlate suggesting that the steel contains a large number of dissimilar particles.

\section{DISCUSSION}

The present steel contains 0.93 wt. ppm boron (Table 1) which corresponds to an atom ppm concentration of $0.93 \times 55.8 / 10.8$ or 4.8 at. ppm which would be made up of 3.9 at. ppm of ${ }^{11} \mathrm{~B}$ and 0.9 at. ppm of ${ }^{10} \mathrm{~B}$. Even at these low concentrations boron can modify the mechanical properties of ferritic steels depending upon the distribution within the microstructure (4 and 9). Moreover when subjected to neutron irradiation and, in particular, to a thermal neutron component of the total neutron flux, there is the potential for the ${ }^{10} \mathrm{~B}$ isotope $(18 \%$ of the total $\mathrm{B})$ to be transmuted to He and Li by the following $(n, \alpha)$ reaction (8).

${ }^{10} \mathrm{~B}+{ }^{1} \mathrm{n}={ }^{7} \mathrm{Li}(0.87 \mathrm{MeV})+{ }^{4} \mathrm{He}(1.53 \mathrm{MeV})$

with transmutation products being emitted with significant energy. The transmutation of ${ }^{10} \mathrm{~B}$ by thermal neutrons is accompanied by local irradiation displacement damage events in the $\alpha$ iron lattice. Since the transmutation products $\mathrm{He}$ and $\mathrm{Li}$ are emitted with energies of 1.53 and 0.87 $\mathrm{MeV}$ respectively, the resulting damage events cause energy loss and the ions are brought to rest within defined radial distances of $\sim 3.0$ and $\sim 1.5 \mu \mathrm{m}$ respectively, from the site of the transmutation event (8). However, the distribution of boron within the overall microstructure is central to how it can influence the mechanical properties (4). As a consequence it is important to consider the distribution of the $\mathrm{B}$ within the overall microstructure of ferritic steels as the role of the boron impurity could depend on whether it is present as free atomic species or incorporated into specific microstructural features, such as inclusions or precipitates or grain boundaries. 
If all the boron were free to diffuse to grain boundaries it may, as a result of being subjected to neutron irradiation cause damage along the path of the grain boundary resulting in a lowering of the grain boundary energy and hence a reduction in mechanical properties. However, boron is present to less than $1 \mathrm{wt}$. ppm in this steel and there may be insufficient free boron to result in a measurable increase in concentration at the the grain boundaries. To determine if there is sufficient boron to segregate to the grain boundaries consider an idealised grain boundary structure. In 3-D polycrystalline materials the grains are surrounded by grain faces which meet to form three-fold grain edges, which in turn meet to form four-fold vertices or nodes $(10,11)$. If the faces all have the same energy they meet, in equilibrium, at an angle of $120^{\circ}$ and the edges meet at the nodes at $109^{\circ} 28^{\prime}$. No array of regular flat-faced polyhedra satisfies these conditions. However a body centred cubic array of identical 14-hedra (tetrakaidecahedra) with six square and eight regular hexagonal faces, Figure 4 (a), provides a reasonable approximation (12). For simplicity in these calculations we approximate this to a 2-D array of regular hexagons with a grain size of $30 \mu \mathrm{m}$ as shown in Figure 4 (b).

The length of grain boundary in an area $200 \mu \mathrm{m}$ x $150 \mu \mathrm{m}$ would be approx $2 \mathrm{~mm}$ which would require approximately $7 \times 10^{6}$ atoms to occupy all grain sites assuming an atom spacing of 0.3 $\mathrm{nm}$. If the grain size is reduced to $10 \mu \mathrm{m}$ then the grain boundary length increases to approximately $6.5 \mathrm{~mm}$ which would require approximately $2.1 \times 10^{7}$ atoms to occupy all sites. The total number of boron atoms available to diffuse to the grain boundaries in this area is $\sim 1.6$ $\mathrm{x} 10^{6}$. This number is calculated assuming an atom spacing of $0.3 \mathrm{~nm}$ and a boron concentration of 0.93 wt. ppm which corresponds to a boron concentration of 4.8 atom ppm. There are therefore an insufficient number of boron atoms to completely fill all grain boundary sites assuming either a $10 \mu \mathrm{m}$ or $30 \mu \mathrm{m}$ grain size. However if all the boron atoms were to diffuse to the grain boundaries then there would be a boron concentration of between 7 and 22 at.\%. The ${ }^{10} \mathrm{~B}$ concentration would be between 2 and $4 \%$ which would correspond to a spacing of between 50 and 25 atoms or 15 and $7.5 \mathrm{~nm}$. Clearly this would result in evidence of grain boundary boron in the SIMs distribution maps shown in Figure 3. Since the radial damage distances for the $\mathrm{He}$ and $\mathrm{Li}$ decay products are $\sim 3.0 \mu \mathrm{m}$ and $\sim 1.5 \mu \mathrm{m}$ respectively, there is more than sufficient boron to potentially influence in the mechanical properties of the steel. 
The ${ }^{10} \mathrm{~B}$ and ${ }^{11} \mathrm{~B}$ maps shown in figures 3 and 4 all show good register with the boron associated with second phase particles, inclusions or precipitates. However, it may be that the boron concentration at the grain boundary is too low to be detected by the SIMS system. To determine if the concentration of boron in the second phase particles would account for the total boron concentration an overall audit has been undertaken. Image analysis has been performed on both the ${ }^{10} \mathrm{~B}$ and ${ }^{11} \mathrm{~B}$ maps which were each recorded from an area $200 \mu \mathrm{m} \times 150 \mu \mathrm{m}$ with a resolution of $640 \times 480$ pixels. For all analyses an intensity threshold of 100 was used from a potential of 256 and analyses were performed using minimum pixel sizes of 1, 2, 4, 6, 9, 12 and 21. These pixel numbers were employed because these would give reliable data concerning areas of boron containing second phase particles. The logic is illustrated in Figure 5. Here particles with a size less than 1 pixel will generally excite 1,2 or 4 pixels, those with size between 1 and 2 pixels will excite 4,6 or 9 pixels while those with size greater than 2 but less than 3 pixels will excite 9,12 or 16 pixels. The ${ }^{10} \mathrm{~B}$ map has a lower signal to noise level than the ${ }^{11} \mathrm{~B}$ and using a minimum pixel level of 1 pixel resulted in too many objects being detected

Generally there was good agreement between the image analysis for the ${ }^{10} \mathrm{~B}$ and ${ }^{11} \mathrm{~B}$ maps particularly for greater than 2 pixel particles. Table 2 lists the number of particles detected and their total area for pixel sizes from 1 to 21 . Although a large number of 1 and 2 pixel particles were detected the total area of particles detected did not significantly change between 2 pixels and 12 pixels. The image analysis program will always over-estimate the total area because a particle can excite a pixel whilst only occupying a fraction of its area. The 6 pixel size gave the most reliable indication of particle area with error bars from 2 to 12 pixels. Each pixel represents a size $0.3125 \mu \mathrm{m} \times 0.3125 \mu \mathrm{m}$ or an area $0.098 \mu \mathrm{m}^{2}$ and converting pixel areas to true areas results in an area of boron containing inclusions or precipitates of $125 \pm 12 \mu \mathrm{m}^{2}$.

The size distribution of particles from $0.5 \mu \mathrm{m}$ to $2.75 \mu \mathrm{m}$ is shown in figure 6 . No particles were found with a size greater than $2.75 \mu \mathrm{m}$. There appears to be a mean particle size of approximately $1.5 \mu \mathrm{m}$ if the 1 and 2 pixel thresholds are ignored. The area of boron containing particles is $125 \pm 12 \mu \mathrm{m}$. If all the boron in the steel is located in these particles the concentration of ${ }^{10} \mathrm{~B}$ and ${ }^{11} \mathrm{~B}$ is 0.02 and 0.09 atom percent respectively. This corresponds to approximately $200{ }^{10} \mathrm{~B}$ atoms per pixel. Earlier in this paper we considered whether it would be possible to detect ${ }^{11} \mathrm{~B}$ segregation to grain boundaries to 12 atom percent of the grain boundary sites. If there were to have been a boron segregation of 12 atom percent along a grain boundary 
this would correspond to a maximum of 170 atoms per pixel. This is a similar number per pixel to that observed in the particles. Therefore if segregation of boron to grain boundaries had occurred it would have been detected. It is therefore reasonable to assume that all the boron is located in the particles and not at the grain boundaries.

Location of the boron is relatively straightforward and it has been demonstrated that the boron is associated with inclusions or precipitates. However it is only present in these particles to $<0.1$ at. $\%$ and must be present in association with another metallic element. Chemical analysis, see Table 1, indicates that only silicon (0.18 wt.\%), manganese (1.33 wt.\%) and aluminium (0.06 wt.\%) are present in significant quantities. Examination of element maps for $\mathrm{Mn}, \mathrm{Si}$ and $\mathrm{Al}$, Figure 3, show that $\mathrm{Al}+\mathrm{B}, \mathrm{Al}+\mathrm{Si}+\mathrm{B}$ and $\mathrm{Fe}+\mathrm{B}$ particles are present with the latter being dominant. Consistent with previous observations by Jones et al (4) the boron was not associated with Mn rich precipitates, possibly MnS. Maps for carbon and boron combinations also failed to match with the boron locations. It must therefore be concluded that the boron is associated mainly with iron and or iron oxide particles within the matrix, which implies that the boron was incorporated during early stages of the heat treatment cycle of the steel.

\section{CONCLUSIONS}

1) Boron chemically combines with inclusions and precipitates within the C-Mn steel plate and is present to less than 0.1 atom percent

2) All the boron present in the steels can be accounted for in the inclusions and precipitates and this is supported by the fact that there was no evidence of boron segregated to grain boundaries.

Acknowledgement. P E J Flewitt would like to thank BNFL-British Nuclear Group for allowing time to work at Bristol University. 


\section{REFERENCES}

1) Flewitt P E J, Williams G H and Wright M B, Mat. Sci. and Tech., 9, 75, 1993.

2) Younes C M, Flewitt P E J, Heard P J and Wild R K, Met. Mat. Trans., 31A, 617, 2000.

3) Flewitt P E J and Wild R K, Grain Boundaries: Their Microstructure and Chemistry, J Wiley (Chichester) 2001.

4) Jones R B, Younes C M, Heard P J, Wild R K and Flewitt P E J, Acta. Mat., 50, 4395, 2002.

5) Flewitt P E J and Moskovic R, Mat. Science and Technology, 20, 553, 2004.

6) $\mathrm{Wu}$ R, Freeman A J and Olsen G J, Science, 265, 1007, 1994.

7) Jones R B and Bolton C J, 24 ${ }^{\text {th }}$ reactor safety meeting USNRC Oct. 1996 Bethesda USA; NOREG/CP-1057, 2, 25, 1997.

8) Harries D R J. Br. Nucl. Energy Soc.; 8:74-87, 1966.

9) Oliver B M, McElroy W N, Kellog I S and Farrar H., Reactor dosimetry, ASTM STP 1288. Philadelphia: ASTM, 1994.

10) Smith C S, Metal Interfaces, 65, ASM (Cleveland) 1952.

11) Smith C S, Acta Metall, 1, 244, 1953.

12) Thomson W (Lord Kelvin), Philos. Mag., 25, 503, 1887. 
Table 1

Chemical composition of VSA steel used in this study (wt.\%)

\begin{tabular}{|l|l|l|l|l|l|l|l|l|l|l|l|l|l|l|}
\hline Si & Mn & S & P & Mo & Al & Cu & Cr & Sn & V & C & O & N & B & Fe \\
\hline 0.18 & 1.33 & 0.002 & 0.005 & $<0.005$ & 0.006 & $<0.02$ & $<0.02$ & $<0.02$ & $<0.005$ & 0.13 & 0.003 & 0.006 & 0.93 & Bal \\
\hline
\end{tabular}

Table 2

Summary of Image Analysis on ${ }^{11} \mathrm{~B}$ map

\begin{tabular}{|c|c|c|}
\hline Pixel Size Used & $\begin{array}{c}\text { Number of } \\
\text { Particles } \\
\text { Detected }\end{array}$ & Area $(\mu \mathrm{m})$ \\
\hline 1 & 485 & 176 \\
\hline 2 & 105 & 137 \\
\hline 4 & 60 & 129 \\
\hline 6 & 51 & 125 \\
\hline 9 & 46 & 122 \\
\hline 12 & 42 & 118 \\
\hline 21 & 29 & 98 \\
\hline
\end{tabular}


(1)

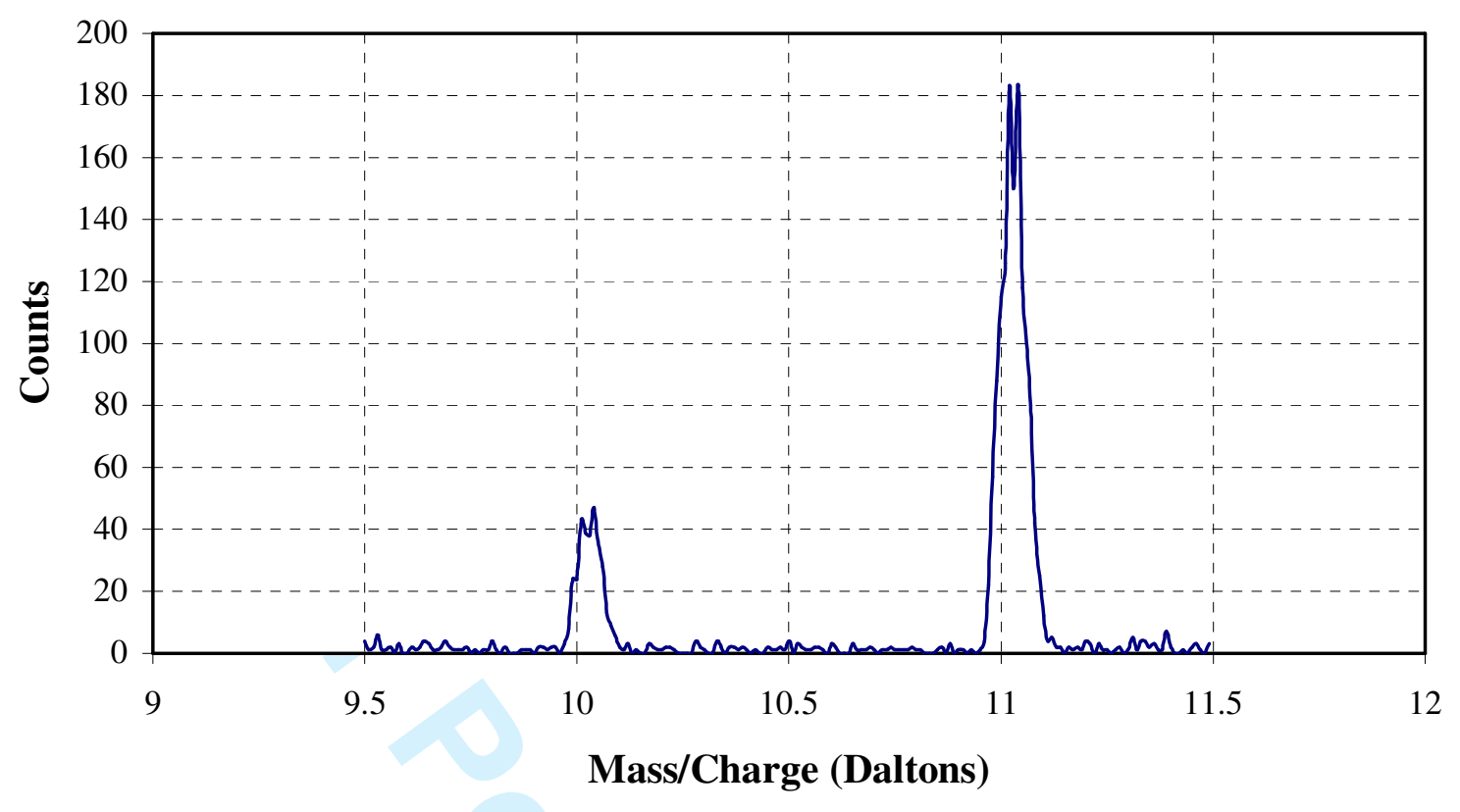

Figure 1 Secondary ion mass spectrum recorded from an area of the surface of the polished C-Mn steel. 
(2)

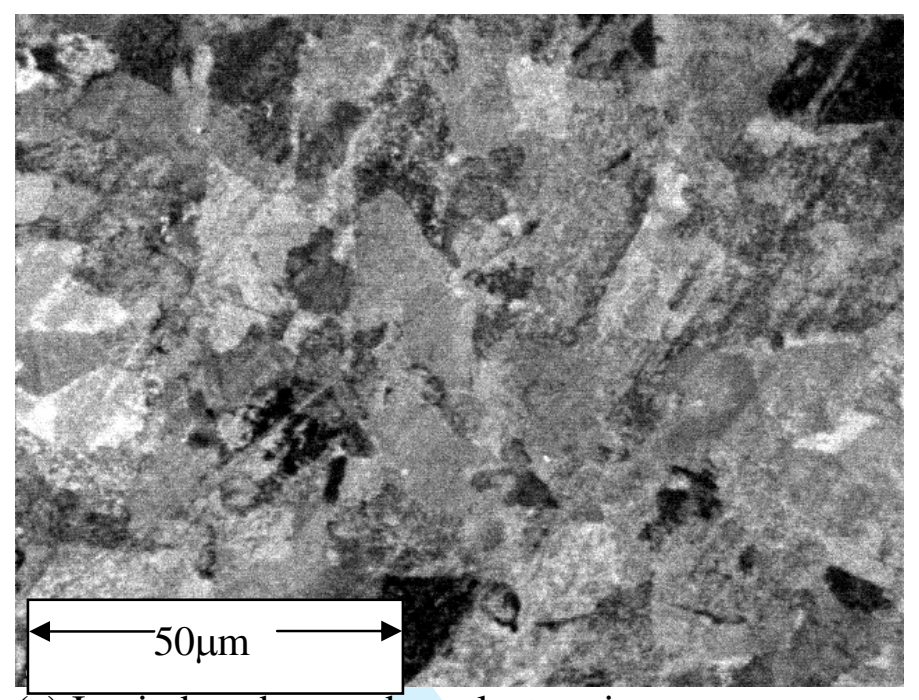

(a) Ion induced secondary electron image

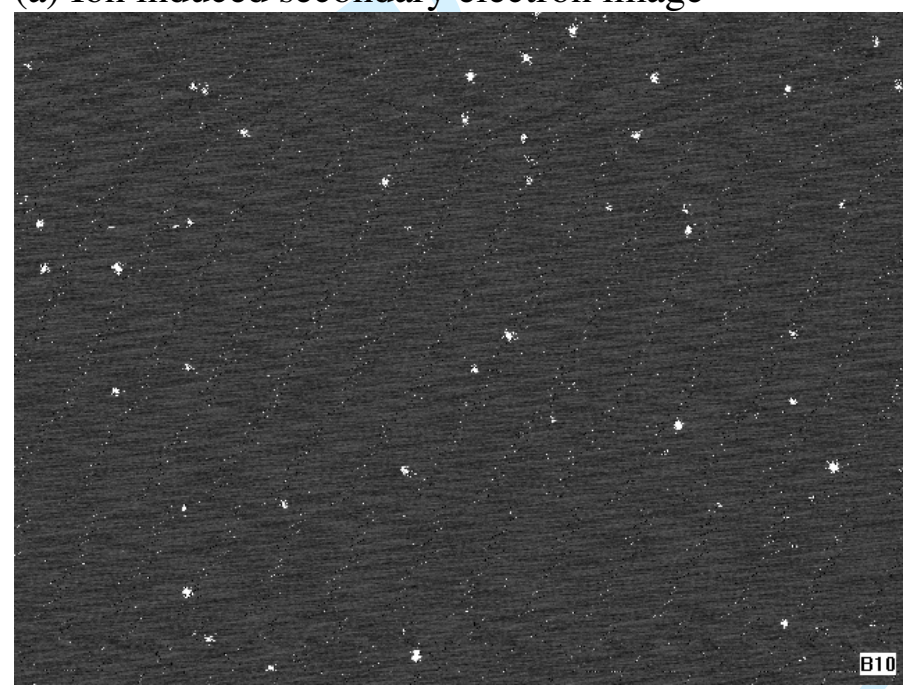

(b) ${ }^{10} \mathrm{~B}$ ion image

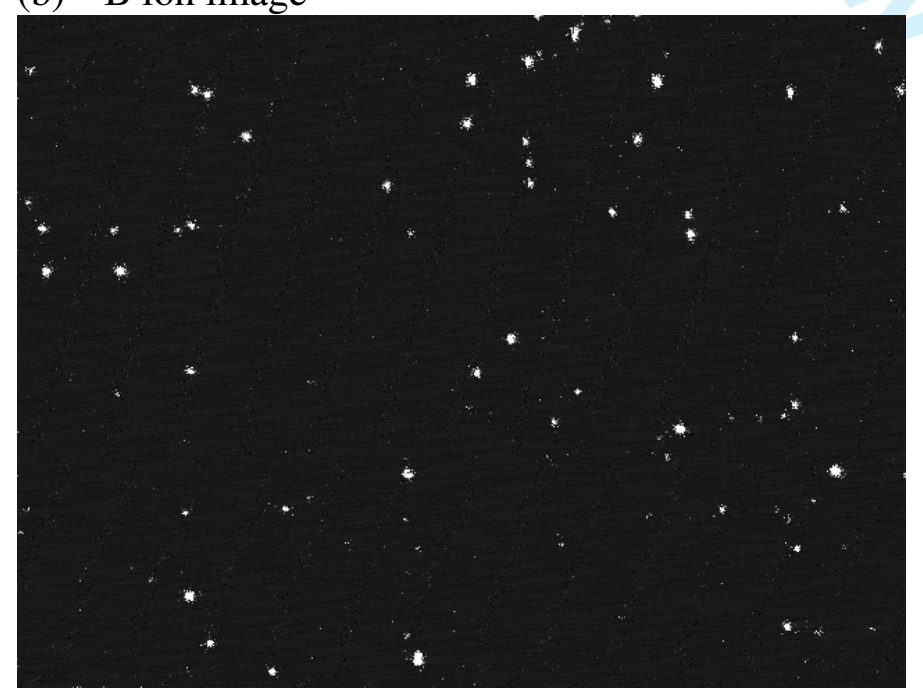

(c) ${ }^{11} \mathrm{~B}$ ion image

Figure 2. Ion induced secondary electron image of the C-Mn steel (a) and ion images for (b) ${ }^{10} \mathrm{~B}^{+}$and (c) ${ }^{11} \mathrm{~B}^{+}$(Image is used here for $\mathrm{b}$ and $\mathrm{c}$ and maps in Figure 3 ). 
(3)

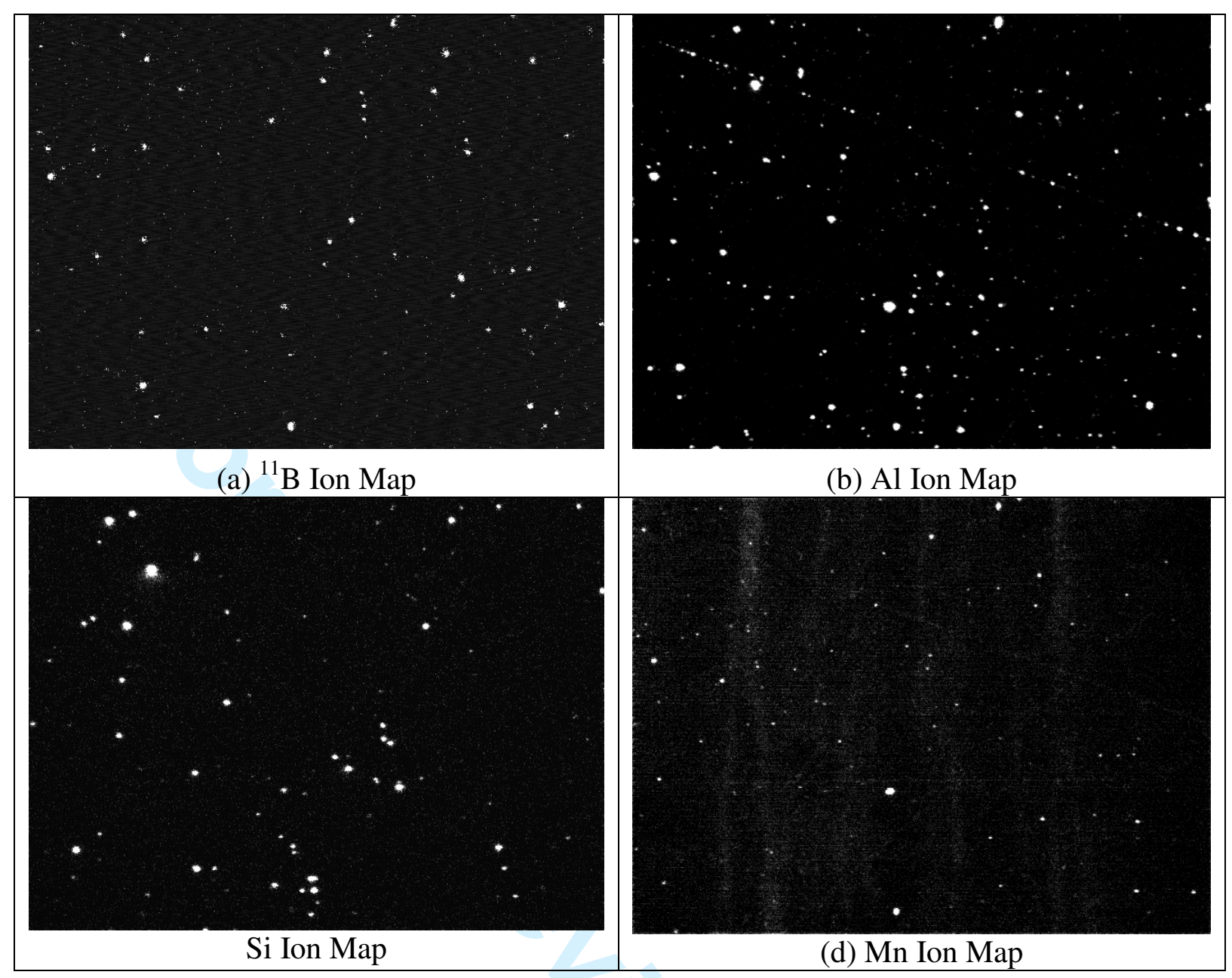

Figure 3. Secondary ion maps showing the distribution of (a) ${ }^{11} \mathrm{~B}^{+}$; (b) $\mathrm{Al}^{+}$; (c) $\mathrm{Si}^{+}$and (d) $\mathrm{Mn}^{+}$. 


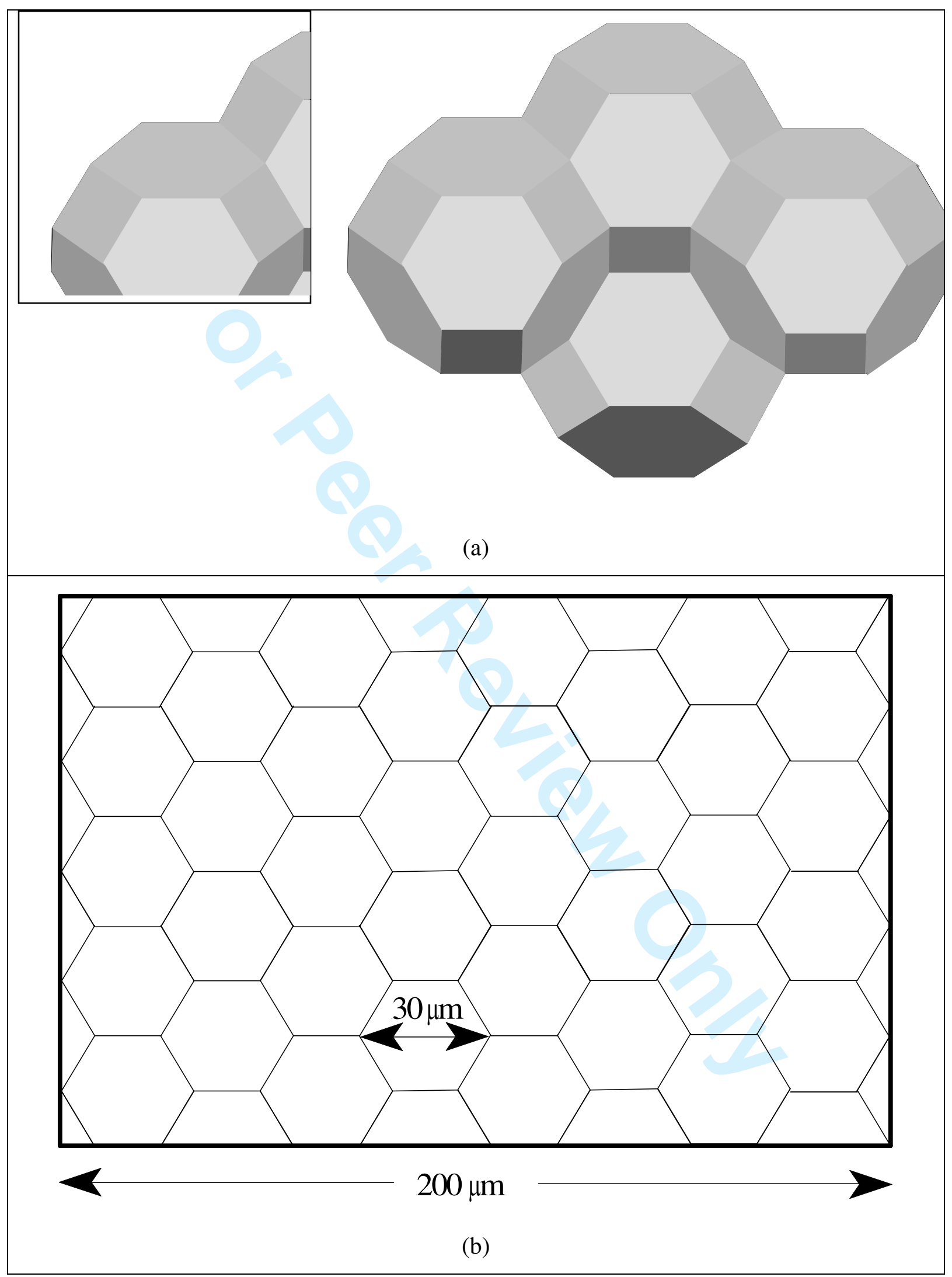

Figure 4 (a) A body centred cubic 3-D array of identical 14-hedra (tetrakaidecahedra) with six square and eight regular hexagonal faces, (b) a corresponding idealised 2-D grain 
(5)

structure with grain size of $30 \mu \mathrm{m}$. 
(6)

\section{Particle diameter $<1$ pixel}
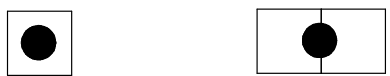

Pixels 1

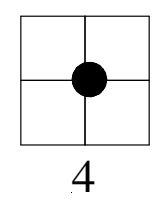

Particle diameter $>1$ pixel $<2$ pixels
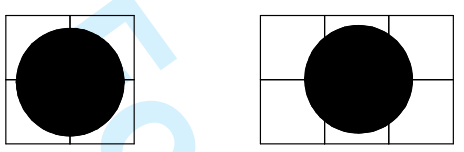

6

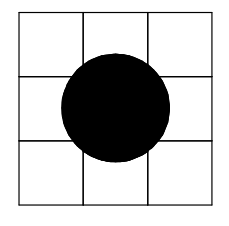

9

Particle diameter $>2$ pixels $<3$ pixels
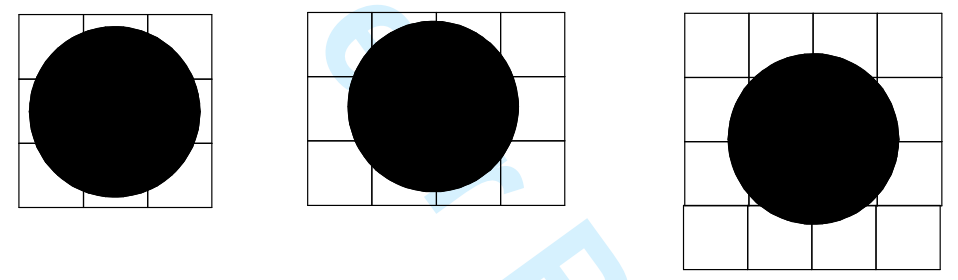

16

9

12

Pixels

Figure 5 Schematic diagram showing relation between particle size (diameter) and number of pixels excited (1 to 16 pixels). 
(7)

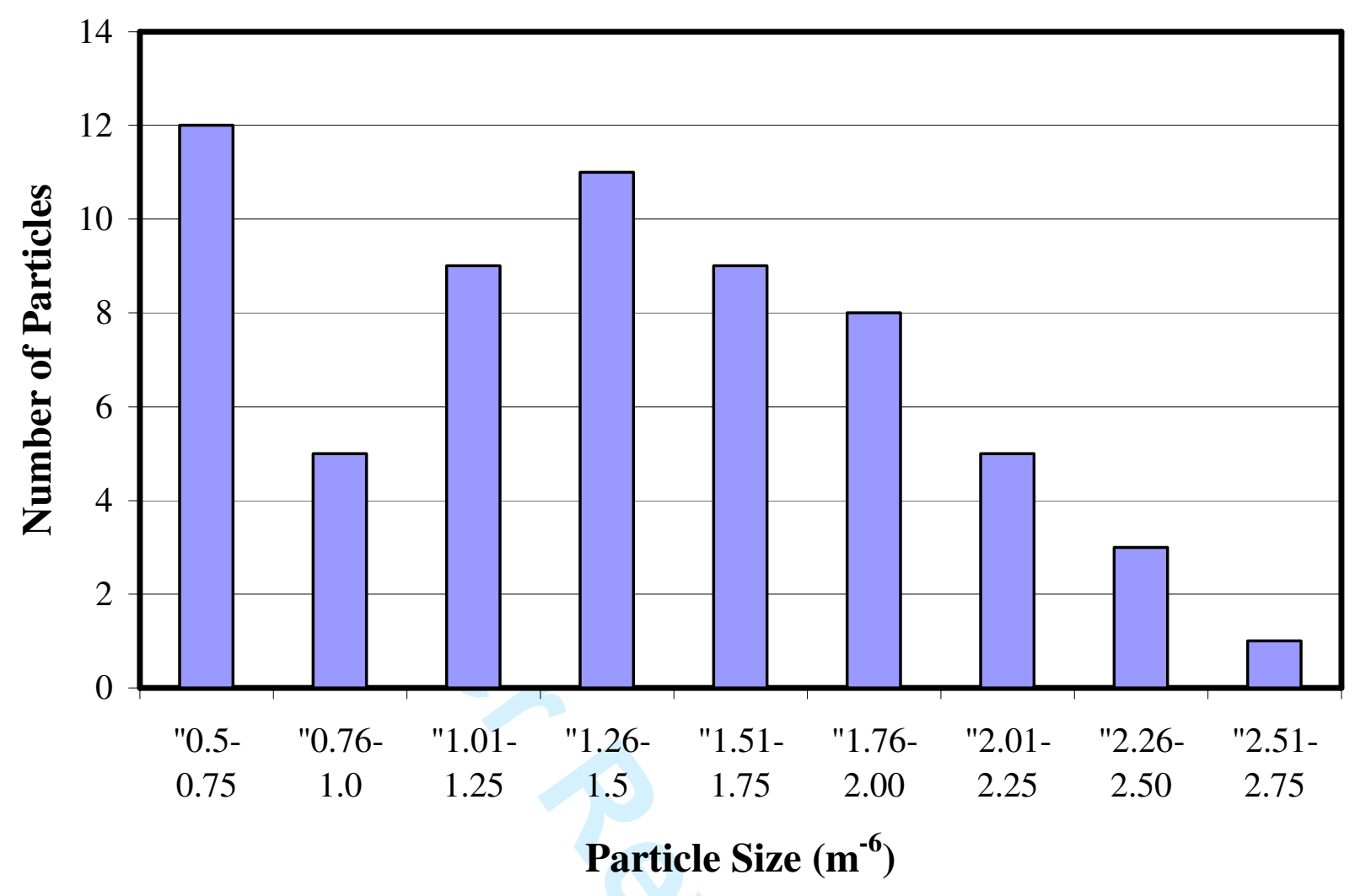

Figure 6 Histogram of the size of boron containing particles. 